\title{
Exosomal miRNAs as biomarkers for prostate cancer
}

\author{
Nina Pettersen Hessvik ${ }^{1,2}$, Kirsten Sandvig ${ }^{1,2,3}$ and Alicia Llorente ${ }^{1,2 *}$ \\ 1 Department of Biochemistry, Institute for Cancer Research, Oslo University Hospital - The Norwegian Radium Hospital, Oslo, Norway \\ ${ }^{2}$ Centre for Cancer Biomedicine, Faculty of Medicine, University of Oslo, Oslo, Norway \\ ${ }^{3}$ Department of Biosciences, University of Oslo, Oslo, Norway
}

Edited by:

William Cho, Queen Elizabeth

Hospital, Hong Kong

Reviewed by:

Francesca Fanini, Istituto Scientifico

Romagnolo per lo Studio e la Cura dei

Tumori, Italy

Alessio Paone, Ohio State University, USA

\section{*Correspondence:}

Alicia Llorente, Department of Biochemistry, Oslo University

Hospital - The Norwegian Radium

Hospital, Ullernchausseen 70 ,

Montebello, 0379 Oslo, Norway.

e-mail: alicia.martinez.llorente@

rr-research.no
miRNAs are small non-coding RNAs that finely regulate gene expression in cells. Alterations in miRNA expression have been associated with development of cancer, and miRNAs are now being investigated as biomarkers for cancer as well as other diseases. Recently, miRNAs have been found outside cells in body fluids. Extracellular miRNAs exist in different forms - associated with Ago2 proteins, loaded into extracellular vesicles (exosomes, microvesicles, or apoptotic bodies) or into high density lipoprotein particles. These extracellular miRNAs are probably products of distinct cellular processes, and might therefore play different roles. However, their functions in vivo are currently unknown. In spite of this, they are considered as promising, non-invasive diagnostic, and prognostic tools. Prostate cancer is the most common cancer in men in the Western world, but the currently used biomarker (prostate specific antigen) has low specificity. Therefore, novel biomarkers are highly needed. In this review we will discuss possible biological functions of extracellular miRNAs, as well as the potential use of miRNAs from extracellular vesicles as biomarkers for prostate cancer.

Keywords: exosomes, microvesicles, extracellular miRNA, prostate cancer, biofluids, biomarkers

\section{INTRODUCTION}

miRNAs are 19-23 nucleotides long non-coding RNAs that play important gene-regulatory roles (Carrington and Ambros, 2003; Bartel, 2004). These small RNAs downregulate gene expression through incorporation into the RNA-induced silencing complex (RISC), which then binds to partially complementary sites mainly in the $3^{\prime}$ untranslated region $\left(3^{\prime} \mathrm{UTR}\right)$ of their mRNA targets (Bartel, 2004). Depending on pairing complementarity, miRNAs operate through translation repression, mRNA cleavage or destabilization, or a combination of these routes (Lee et al., 1993; Wightman et al., 1993; Hutvagner and Zamore, 2002; Song et al., 2004; Lim et al., 2005). Several cellular processes like proliferation, differentiation, and apoptosis are shown to be regulated by miRNAs (Bartel, 2004) and miRNAs are found aberrantly expressed in many types of cancer (Calin et al., 2005; Iorio et al., 2005; Lu et al., 2005; Volinia et al., 2006; Porkka et al., 2007; Croce, 2009). Moreover, studies using knockout mice and transgenic mice overexpressing certain miRNAs indicate that miRNAs do contribute to cancer development (Mu et al., 2009; Hatley et al., 2010; Medina et al., 2010). It has been shown that miRNAs can act both as oncogenes and tumor suppressors, and that they participate in cancer development by regulating cell cycle, cellular senescence, DNA damage response, and apoptosis (Lima et al., 2011; Jansson and Lund, 2012).

Prostate cancer is the most commonly diagnosed cancer in men and the second leading cause of death among men with cancer in the Western world (Ferlay et al., 2007; Jemal et al., 2009). A protein mainly secreted by prostate cells, prostate specific antigen (PSA), has been used as a blood-based biomarker for prostate cancer for several decades. Even though PSA is a valuable tool, it lacks specificity and is therefore not considered an optimal biomarker
(Nogueira et al., 2010). Thus, new and specific markers for prostate cancer are highly needed. Several miRNA expression profiles have been reported for prostate cancer, showing altered expression levels in prostate cancer tissue compared to control tissue (Lu et al., 2005; Volinia et al., 2006; Ozen et al., 2007; Porkka et al., 2007; Ambs et al., 2008; Szczyrba et al., 2010). Importantly, miRNAs are currently being investigated as prognostic and diagnostic tools for prostate and other types of cancer (Sørensen and Ørntoft, 2009; Kuner et al., 2013).

\section{FORMS OF EXTRACELLULAR mIRNAs}

Recently, miRNAs have been identified in the medium from cultured cells (Valadi et al., 2007) and in many body fluids like blood (Chim et al., 2008; Lawrie et al., 2008), urine (Hanke et al., 2010), saliva (Park et al., 2009), breast milk (Kosaka et al., 2010b; Weber et al., 2010), and seminal plasma (Weber et al., 2010). Some of these miRNAs appear in extracellular stable forms, which render them interesting as biomarkers for cancer and other diseases. Extracellular miRNA can be found in different forms (Figure 1); some miRNAs are loaded into exosomes or microvesicles (Hunter et al., 2008; Skog et al., 2008; Lasser et al., 2011; Gallo et al., 2012; Hessvik et al., 2012), into apoptotic bodies (Zernecke et al., 2009), or into high density lipoprotein particles (Vickers et al., 2011), whereas others are associated with Ago2 proteins - proteins which are part of RISC (Arroyo et al., 2011; Turchinovich et al., 2011). Common to all these forms is that the miRNAs are not degraded by RNase treatment (Valadi et al., 2007; Turchinovich et al., 2011). First, the stability of extracellular miRNAs against RNases was thought to be mainly due to incorporation of miRNAs into small extracellular vesicles (Valadi et al., 2007; Hunter et al., 2008). However, some reports have shown that most of the extracellular miRNAs 


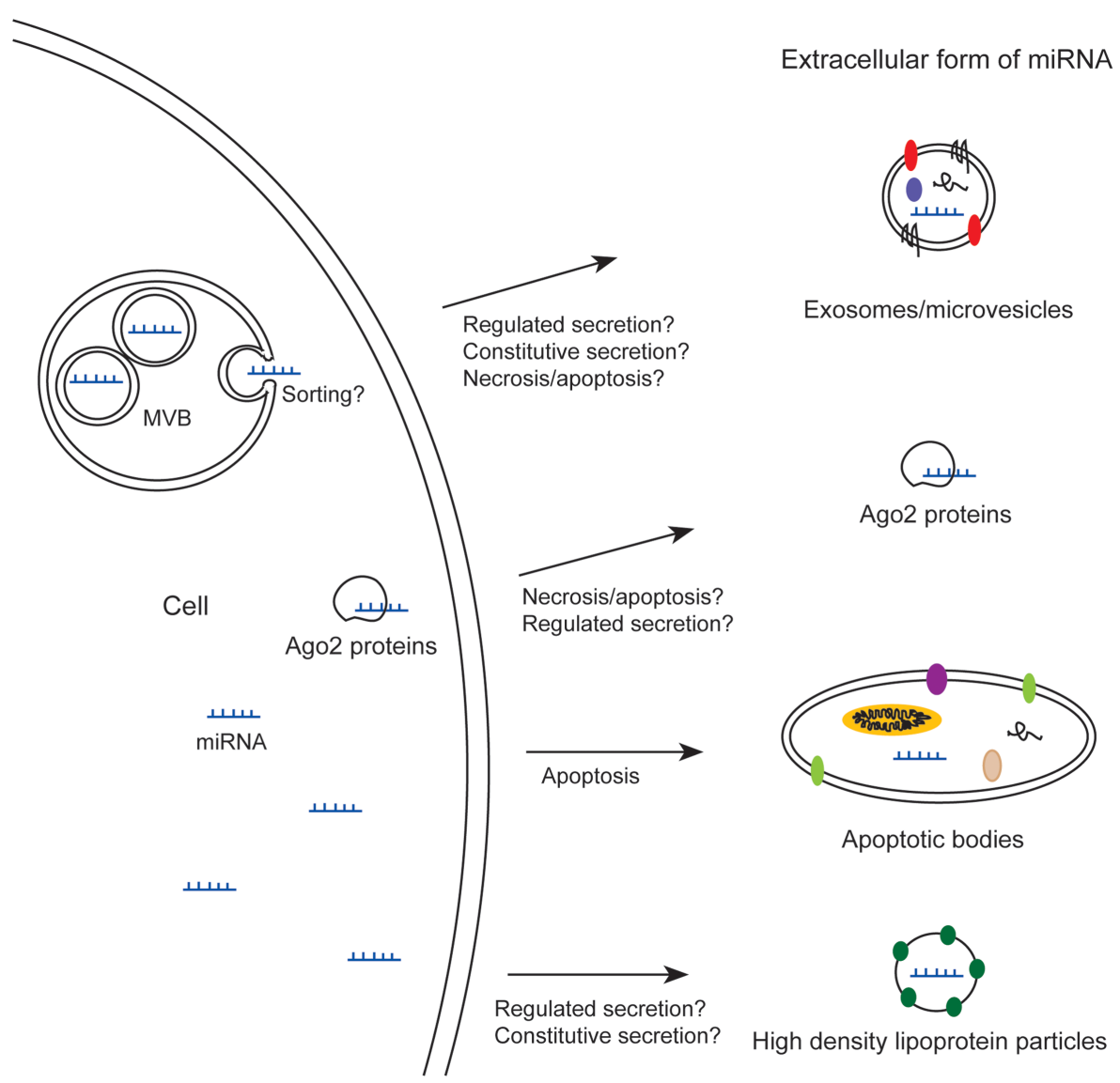

FIGURE 1 | Extracellular miRNAs exist in different forms; loaded into exosomes/microvesicles, apoptotic bodies, or high density lipoprotein particles, or associated with Ago2 proteins. MVB, multivesicular body.

in plasma and cell culture media are found outside vesicles, in stable complexes with Ago2 proteins (Arroyo et al., 2011; Turchinovich et al., 2011), although a recent publication showed that the majority of miRNAs in serum and saliva is enclosed in exosomes (Gallo et al., 2012).

\section{EXTRACELLULAR VESICLES}

As mentioned, miRNAs have been found in several types of extracellular vesicles. Extracellular vesicles are mainly classified based on the different mechanism of release, but a consensus in the terminology used to name these small vesicles is still lacking. Normally, exosomes are defined as small membrane vesicles with a diameter of $40-100 \mathrm{~nm}$ that are secreted when multivesicular bodies (MVBs) fuse with the plasma membrane (Pan et al., 1985; Johnstone et al., 1987; Bobrie et al., 2011). Shedding vesicles or microparticles are $0.1-1 \mu \mathrm{m}$ in diameter and formed by budding from the plasma membrane (Cocucci et al., 2009). To collectively describe both exosomes and shedding vesicles the term microvesicles is often used (Cocucci et al., 2009), though this term is sometimes also used to indicate either one of these types of vesicles. A third type of extracellular vesicles is apoptotic bodies, which are $1-4 \mu \mathrm{m}$ in diameter and formed during apoptosis (Hristov et al., 2004; Zernecke et al., 2009). Recently, the term extracellular vesicles has been used to describe these three classes of vesicles as a group (Kalra et al., 2012).

\section{POTENTIAL ROLES OF EXTRACELLULAR mIRNAs}

Whether the extracellular forms of miRNAs are simply waste products from cells or have a biological function, such as participating in intercellular communication is not yet clear. There are reports showing increased level of miRNAs in blood upon organ toxicity (Laterza et al., 2009; Zhang et al., 2010; Pritchard et al., 2012), and this could of course represent waste products. Nevertheless, since the various forms of extracellular miRNAs are probably products of distinct cellular processes, they might play different roles, and therefore it is important to distinguish between them. Apoptotic bodies are by definition formed during apoptosis. miRNA bound to Ago 2 may be released from cells upon apoptosis or necrosis (Turchinovich et al., 2011), but it is not known if miRNA-Ago2 complexes also can be transported out of viable cells. This means that miRNAs bound to Ago2 proteins and miRNAs incorporated into apoptotic bodies might solely be by-products from dying cells or represent a way for dying cells to communicate with neighboring cells. They could represent a signal warning the organism about cellular dysfunction. 
Shedding vesicles and exosomes are thought to be released by viable cells, though it is not ruled out whether these vesicles also are released by dying cells. Therefore, these vesicles have to a greater extent been suggested to play a role in intercellular signaling (Valadi et al., 2007; Hunter et al., 2008). Indeed, it has been shown that miRNAs can be transferred by exosomes from one cell to another in vitro and result in downregulation of target genes in the recipient cell (Kosaka et al., 2010a; Kogure et al., 2011; Mittelbrunn et al., 2011; Montecalvo et al., 2012). This finding is intriguing and indicates a role in intercellular communication which could have a huge impact. Yet this remains to be shown in vivo. Interestingly, it has been reported that injection of exosomes loaded with siRNA into mice can result in specific gene knockdown in certain cells (Alvarez Erviti et al., 2011). It has been questioned whether the concentration of exosomes in biological fluids is high enough to play a role in intercellular communication, but this does not exclude a role in autocrine or paracrine signaling (Turchinovich et al., 2011; Sverdlov, 2012). Exosomes probably exert their effect on neighboring cells, and thereby participate in creating a specific microenvironment. In this scenario, the exosomes found in body fluids would only be residual amounts, representing a secondary effect.

In addition to their conventional role in post-transcriptional gene regulation, a new role for miRNAs as signaling molecules has recently been described by two independent groups. Interestingly, extracellular let-7 was shown to activate Toll-like receptor 7 in neurons and induce neurodegeneration (Lehmann et al., 2012). By another group, exosomal miR-21 and miR-29a was shown to activate Toll-like receptor 7 and 8 in immune cells, triggering a prometastatic inflammatory response that may lead to tumor growth and metastasis (Fabbri et al., 2012). Thus, extracellular miRNAs could be important regulators of tumor microenvironment as well as exacerbate CNS damage, through agonistic effect on Toll-like receptor 7 and 8 .

Another possible role for miRNAs in exosomes and MVBs is that they might function together with the RNAi machinery. RISC proteins have been shown to be associated with MVBs and exosomes (Gibbings et al., 2009; Lee et al., 2009). Moreover, blocking MVB formation by depletion of ESCRT (endosomal sorting complex required for transport) components has been reported to result in impaired miRNA silencing, indicating a role in RNAi dynamics (Gibbings et al., 2009; Lee et al., 2009).

\section{ARE mIRNAs SORTED INTO EXOSOMES?}

Another debated issue in the field is whether miRNAs are sorted into MVBs and exosomes or not. Several reports have shown that certain miRNAs are selectively identified or expressed at a higher level in exosomes than in parent cells (Valadi et al., 2007; Ohshima et al., 2010; Kogure et al., 2011; Mittelbrunn et al., 2011; Hessvik et al., 2012), indicating a sorting of miRNAs into MVBs. The opposite situation has also been reported; for example one study showed that only $2 \%$ of the most abundant miRNA in a breast cancer cell line, miR-720, was found extracellularly, whereas many other miRNAs were presented at comparable levels in the cellular and extracellular populations (Pigati et al., 2010). The findings that certain miRNAs are either enriched in exosomes or retained in cells, indicate that exosomal miRNAs are not simply unsorted waste products from cells. The mechanisms controlling the selection of miRNAs into exosomes or the retention of miRNAs inside cells still remain unknown. Though, it cannot be excluded that the higher expression level of certain miRNAs in exosomes is due to shielding of miRNAs from degradation by exosome membranes, and not due to a sorting mechanism. Moreover, Kim et al. (2012) recently reported that small RNAs with low GC content can be lost during RNA isolation from samples with low RNA content, indicating methodological challenges when working with extracellular miRNAs.

Higher levels of exosomes are found in plasma from cancer patients compared to control individuals (Rabinowits et al., 2009; Tavoosidana et al., 2011), suggesting that cancer cells secrete more exosomes than non-cancerous cells. Therefore, measuring exosomal miRNAs could result in less background from normal cells, and they might then serve as superior biomarkers compared to other extracellular miRNAs. However, the currently used protocols for exosome isolation are extensive and time-consuming. New and faster isolation methods need to be established before exosomal miRNAs can be used in routine diagnostics.

\section{miRNAs AND PROSTATE CANCER}

The first profiling of miRNAs in prostate cancer was published in 2007 (Porkka et al., 2007). In this study prostate cancer cell lines and prostate tissue from both benign prostatic hyperplasia and prostate cancer patients were examined. Today, the miRNA expression in prostate cancer has been published in more than 100 reports, showing promising results for miRNAs as tissue-based biomarkers for this disease (Catto et al., 2011). Measurement of extracellular miRNAs obtained from biological fluids constitutes a non-invasive approach for cancer detection and may therefore be preferable. Indeed, several studies (Table 1, and discussed below) have investigated the miRNA profile in serum/plasma from prostate cancer patients, pointing toward the use of miRNAs as blood-based biomarkers (Mitchell et al., 2008; Lodes et al., 2009; Brase et al., 2011; Moltzahn et al., 2011).

In the first study, the level of six miRNAs in serum samples from 25 patients with metastatic prostate cancer and 25 healthy controls was analyzed. The authors found that miR-141 was overexpressed in the prostate cancer group compared to the control group, and that this miRNA had the greatest differential expression among the six tested miRNAs (Mitchell et al., 2008). Later, 667 miRNAs in serum samples from patients with metastatic $(n=7)$ or localized prostate cancer $(n=14)$ were screened. In this study 69 miRNAs were found to be higher expressed in the metastatic tumor group compared to the primary cancer group. Five of the upregulated miRNAs (miR-375, miR-9*, miR-141, miR200b, and miR-516a-3p) were further validated, resulting in the identification of miR-375 and miR-141 as the best markers for high risk prostate cancer (Brase et al., 2011). Another study analyzed the expression of miR-21, miR-141, and miR-221 in plasma from patients with localized/local advanced $(n=26)$ or metastatic $(n=25)$ prostate cancer and healthy controls $(n=20)$. A higher expression level of miR-21 and miR-221, but not statistically significant for miR-141, was observed in plasma from prostate cancer patients compared to controls. Still, all three miRNAs were significantly higher in patients with metastatic prostate cancer than 
Table 1 | Studies of extracellular miRNAs in body fluids from prostate cancer patients.

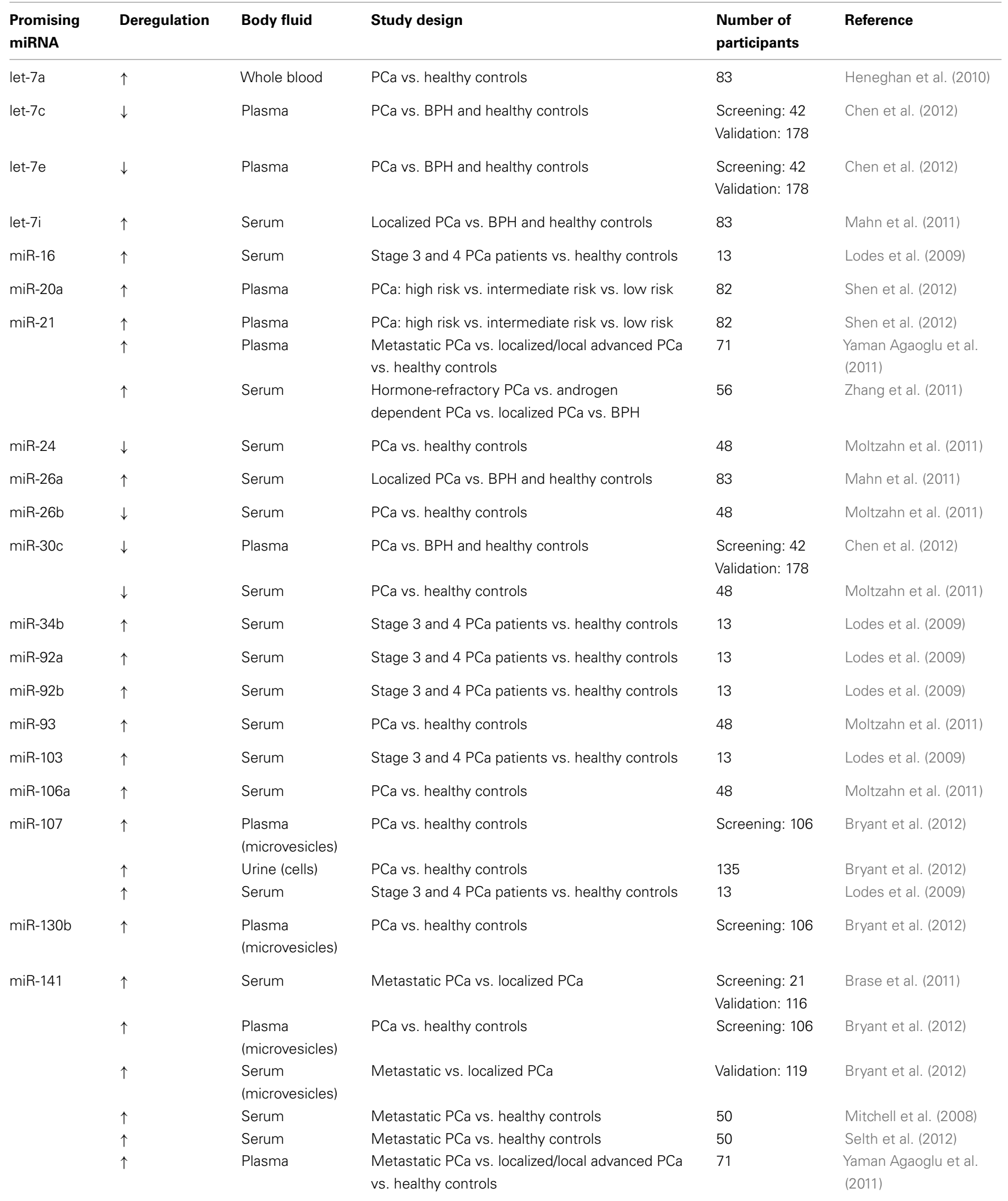

(Continued) 
Table 1 | Continued

\begin{tabular}{|c|c|c|c|c|c|}
\hline $\begin{array}{l}\text { Promising } \\
\text { miRNA }\end{array}$ & Deregulation & Body fluid & Study design & $\begin{array}{l}\text { Number of } \\
\text { participants }\end{array}$ & Reference \\
\hline \multirow[t]{2}{*}{ miR-145 } & $\downarrow$ & Whole blood & PCa vs. healthy controls & 83 & Heneghan et al. (2010) \\
\hline & $\uparrow$ & Plasma & PCa: high risk vs. intermediate risk vs. low risk & 82 & Shen et al. (2012) \\
\hline miR-155 & $\downarrow$ & Whole blood & PCa vs. healthy controls & 83 & Heneghan et al. (2010) \\
\hline $\operatorname{miR}-181 a-2 *$ & $\downarrow$ & $\begin{array}{l}\text { Plasma } \\
\text { (microvesicles) }\end{array}$ & PCa vs. healthy controls & Screening: 106 & Bryant et al. (2012) \\
\hline miR-195 & $\uparrow$ & Serum & Localized PCa vs. BPH and healthy controls & 83 & Mahn et al. (2011) \\
\hline miR-197 & $\uparrow$ & Serum & Stage 3 and 4 PCa patients vs. healthy controls & 13 & Lodes et al. (2009) \\
\hline \multirow[t]{3}{*}{$\operatorname{miR}-221$} & $\uparrow$ & Plasma & PCa: high risk vs. intermediate risk vs. low risk & 82 & Shen et al. (2012) \\
\hline & $\uparrow$ & Plasma & $\begin{array}{l}\text { Metastatic PCa vs. localized/local advanced PCa } \\
\text { vs. healthy controls }\end{array}$ & 71 & $\begin{array}{l}\text { Yaman Agaoglu et al. } \\
\text { (2011) }\end{array}$ \\
\hline & $\uparrow$ & Plasma & PCa vs. healthy controls & 43 & Zheng et al. (2012) \\
\hline miR-223 & $\downarrow$ & Serum & PCa vs. healthy controls & 48 & Moltzahn et al. (2011) \\
\hline miR-298 & $\uparrow$ & Serum & Metastatic PCa vs. healthy controls & 50 & Selth et al. (2012) \\
\hline miR-301a & $\uparrow$ & $\begin{array}{l}\text { Plasma } \\
\text { (microvesicles) }\end{array}$ & PCa vs. healthy controls & Screening: 106 & Bryant et al. (2012) \\
\hline miR-326 & $\uparrow$ & $\begin{array}{l}\text { Plasma } \\
\text { (microvesicles) }\end{array}$ & PCa vs. healthy controls & Screening: 106 & Bryant et al. (2012) \\
\hline miR-328 & $\uparrow$ & Serum & Stage 3 and 4 PCa patients vs. healthy controls & 13 & Lodes et al. (2009) \\
\hline miR-331-3p & $\uparrow$ & $\begin{array}{l}\text { Plasma } \\
\text { (microvesicles) }\end{array}$ & PCa vs. healthy controls & Screening: 106 & Bryant et al. (2012) \\
\hline miR-346 & $\uparrow$ & Serum & Metastatic PCa vs. healthy controls & 50 & Selth et al. (2012) \\
\hline \multirow[t]{4}{*}{$\operatorname{miR}-375$} & $\uparrow$ & Serum & Metastatic PCa vs. localized PCa & Screening: 21 & Brase et al. (2011) \\
\hline & & & & Validation: 116 & \\
\hline & $\uparrow$ & $\begin{array}{l}\text { Serum } \\
\text { (microvesicles) }\end{array}$ & Metastatic vs. localized PCa & Validation: 119 & Bryant et al. (2012) \\
\hline & $\uparrow$ & Serum & Metastatic PCa vs. healthy controls & 50 & Selth et al. (2012) \\
\hline $\operatorname{miR}-432$ & $\uparrow$ & $\begin{array}{l}\text { Plasma } \\
\text { (microvesicles) }\end{array}$ & PCa vs. healthy controls & Screening: 106 & Bryant et al. (2012) \\
\hline $\operatorname{miR}-485-3 p$ & $\uparrow$ & Serum & Stage 3 and 4 PCa patients vs. healthy controls & 13 & Lodes et al. (2009) \\
\hline miR-486-5p & $\uparrow$ & Serum & Stage 3 and 4 PCa patients vs. healthy controls & 13 & Lodes et al. (2009) \\
\hline \multirow[t]{3}{*}{$\operatorname{miR}-574-3 p$} & $\uparrow$ & $\begin{array}{l}\text { Plasma } \\
\text { (microvesicles) }\end{array}$ & PCa vs. healthy controls & Screening: 106 & Bryant et al. (2012) \\
\hline & $\uparrow$ & Urine (cells) & PCa vs. healthy controls & 135 & Bryant et al. (2012) \\
\hline & $\uparrow$ & Serum & Stage 3 and 4 PCa patients vs. healthy controls & 13 & Lodes et al. (2009) \\
\hline \multirow[t]{2}{*}{ miR-622 } & $\uparrow$ & Plasma & PCa vs. BPH and healthy controls & Screening: 42 & Chen et al. (2012) \\
\hline & & & & Validation: 178 & \\
\hline $\operatorname{miR}-625^{*}$ & $\uparrow$ & $\begin{array}{l}\text { Plasma } \\
\text { (microvesicles) }\end{array}$ & PCa vs. healthy controls & Screening: 106 & Bryant et al. (2012) \\
\hline miR-636 & $\uparrow$ & Serum & Stage 3 and 4 PCa patients vs. healthy controls & 13 & Lodes et al. (2009) \\
\hline miR-640 & $\uparrow$ & Serum & Stage 3 and 4 PCa patients vs. healthy controls & 13 & Lodes et al. (2009) \\
\hline miR-766 & $\uparrow$ & Serum & Stage 3 and 4 PCa patients vs. healthy controls & 13 & Lodes et al. (2009) \\
\hline
\end{tabular}


Table 1 | Continued

\begin{tabular}{|c|c|c|c|c|c|}
\hline $\begin{array}{l}\text { Promising } \\
\text { miRNA }\end{array}$ & Deregulation & Body fluid & Study design & $\begin{array}{l}\text { Number of } \\
\text { participants }\end{array}$ & Reference \\
\hline miR-874 & $\uparrow$ & Serum & PCa vs. healthy controls & 48 & Moltzahn et al. (2011) \\
\hline miR-885-5p & $\uparrow$ & Serum & Stage 3 and 4 PCa patients vs. healthy controls & 13 & Lodes et al. (2009) \\
\hline miR-1207-5p & $\uparrow$ & Serum & PCa vs. healthy controls & 48 & Moltzahn et al. (2011) \\
\hline miR-1274a & $\uparrow$ & Serum & PCa vs. healthy controls & 48 & Moltzahn et al. (2011) \\
\hline $\operatorname{miR}-1285$ & $\uparrow$ & Plasma & PCa vs. BPH and healthy controls & $\begin{array}{l}\text { Screening: } 42 \\
\text { Validation: } 178\end{array}$ & Chen et al. (2012) \\
\hline miR-2110 & $\uparrow$ & $\begin{array}{l}\text { Plasma } \\
\text { (microvesicles) }\end{array}$ & PCa vs. healthy controls & Screening: 106 & Bryant et al. (2012) \\
\hline
\end{tabular}

miRNAs ordered by increasing name number. $P C a$, prostate cancer; $B P H$, benign prostatic hyperplasia. Asterisks are part of the miRNA names.

in patients with localized/local advanced disease (Yaman Agaoglu et al., 2011). In a study by Lodes et al. 547 miRNAs were screened, 15 miRNAs (miR-16, -92a, -103, -107, -197, -34b, -328, -485-3p, $-486-5 p,-92 b,-574-3 p,-636,-640,-766,-885-5 p)$ were found to be overexpressed in serum from stage 3 and 4 prostate cancer patients $(n=5)$ compared to eight healthy controls. They also showed a slightly elevated level of miR-141 in stage 3 and 4 prostate cancer patient serum (Lodes et al., 2009). Selth et al. analyzed the expression of 10 miRNAs in serum from patients with metastatic castration-resistant prostate cancer $(n=25)$ and healthy controls $(n=25)$. They found that miR-141, miR-298, miR-346, and miR375 were upregulated in serum from prostate patients compared with controls (Selth et al., 2012). Though these independent studies point toward plasma/serum-derived miR-141 and miR-375 as biomarkers, Mahn et al. (2011) did not succeed in detecting miR-141 in serum samples.

In the study by Mahn et al. the expression of four miRNAs in serum from 37 patients with localized prostate cancer, eight with metastatic prostate cancer, 18 with benign prostatic hyperplasia, and 20 healthy controls was analyzed. They found miR-26a, miR-195, and let-7i to be upregulated in patients with prostate cancer compared with patients with benign prostatic hyperplasia. Moreover, they also showed that miR-26a levels could discriminate patients with prostate cancer from patients with benign prostatic hyperplasia (Mahn et al., 2011). Another report showed results from screening of 384 miRNAs in serum from 36 prostate cancer patients and 12 healthy controls. Five miRNAs (miR-874, -1274a, 1207-5p, -93, and -106a) were identified to be upregulated and four (miR-223, -26b, -30c, and -24) downregulated in cancer patients compared to controls (Moltzahn et al., 2011). Heneghan et al. (2010) analyzed the expression of seven miRNAs and found a decreased level of miR-145 and miR-155 and an increased level of let-7a in whole blood from prostate cancer patients $(n=20)$ compared to healthy controls $(n=63)$.

Although a higher level of miR-21 in plasma from prostate cancer patients compared to controls has been observed (Yaman Agaoglu et al., 2011), Zhang et al. did not find a significant difference in the level of serum-derived miR-21 between patients with benign prostatic hyperplasia $(n=6)$, localized $(n=20)$, and androgen dependent prostate cancer $(n=20)$. Still, higher expression of miR-21 was detected in patients with hormonerefractory prostate cancer $(n=10)$, especially in patients resistant to docetaxel-based chemotherapy, suggesting a potential role for miRNAs as markers for disease progression and response to treatment (Zhang et al., 2011). In another study, the level of miR-221 in plasma samples from healthy controls $(n=20)$, androgen dependent $(n=15)$, and androgen independent $(n=8)$ prostate cancer patients was analyzed. In accordance with the findings by Yaman Agaoglu et al. the authors observed increased expression of miR-221 in plasma samples from prostate cancer patients compared with healthy controls, whereas the level of miR-221 was increased in androgen dependent compared to androgen independent prostate cancer patients (Zheng et al., 2012).

Chen et al. screened the miRNA expression in plasma from 25 prostate cancer patients and 17 patients with benign prostatic hyperplasia and validated candidate miRNAs in a larger independent cohort ( 80 prostate cancer patients, 44 patients with benign prostatic hyperplasia, and 54 healthy controls). These authors showed that five miRNAs (let-7c, let-7e, miR-30c, miR-622, and miR-1285) could differentiate patients with prostate cancer from patients with benign prostatic hyperplasia and healthy controls. They suggested that a panel of the five described miRNAs could distinguish these patient groups from each other with higher sensitivity and specificity compared to one single miRNA (Chen et al., 2012). Another group also suggested a combination of several miRNAs as biomarker after analyzing miRNA levels in plasma samples from 82 prostate cancer patients with varied aggressiveness. In this report the combination of miR-20a, miR-21, miR-145, and miR-221 was shown to distinguish prostate cancer patients with high risk of aggressiveness from those with low risk (Shen et al., 2012).

Neither of the mentioned studies describes in which form the extracellular miRNAs were packaged. In only one study miRNAs from plasma- and serum-derived microvesicles were analyzed, though the vesicles were not well characterized. Eleven miRNAs were found to be differently expressed in prostate cancer patients compared to healthy controls (miR-107, -130b, -141, -181a-2*, 
$-2110,-301 a,-326,-331-3 p,-432,-574-3 p$, and $\left.-625^{*}\right)$, and 16 miRNAs were upregulated in patients with metastases compared to patients without metastases. The association of miR-141 and miR-375 with metastatic prostate cancer was also confirmed. The authors selected five miRNAs that were analyzed in urine samples, showing that miR-107 and miR-574-3p were found in higher concentrations in the urine of men with prostate cancer compared with healthy controls. However, these miRNAs were not really extracellular, since cell pellets from urine were used in this part of the study (Bryant et al., 2012). Recently, we described the miRNA profile in exosomes from the PC-3 metastatic prostate cancer cell line. Among the aforementioned miRNAs suggested as biomarker candidates in clinical studies, we identified 36 in exosomes from PC-3 cells (miR-141, -9*, -200b, -21, -221, -16, -92a, -103, -107, $-197,-92 \mathrm{~b},-574-3 \mathrm{p},-885-5 \mathrm{p},-298,-26 \mathrm{a},-1274 \mathrm{a},-106 \mathrm{a},-26 \mathrm{~b},-30 \mathrm{c}$, -24 , let-7i, let-7a, let-7c, let-7e, miR-1285, -20a, -107, -130b, -301a, $-331-3 p,-625,-485-3 p,-874,-155,-181 a-2^{*}$, and -326) (Hessvik et al., 2012).

As described, an emerging amount of evidence points toward a potential use of blood-based miRNAs as diagnostic and prognostic biomarkers for prostate cancer (Table 1). Nevertheless, the data from the clinical studies are to some extent inconsistent. This may not be surprising due to the fact that these studies differ with respect to experimental design and patient cohort. Most of these studies are small-scale, with varying degree of patient description and few are focusing on cancer-related death or progression free survival as endpoints. At least one study included patients under treatment with chemotherapy, therefore it is uncertain whether the altered miRNA levels were due to the chemotherapy or due to the tumor itself (Lodes et al., 2009). In addition, different platforms have been used to quantify miRNA levels, which also could explain some of the conflicting data. High throughput platforms always have biases and confirmation with a secondary analytical approach, such as RT-qPCR, should be performed to validate the results. Isolation of extracellular miRNAs using different methods can contribute to variation due to low recovery of certain miRNA species, and quantification of extracellular miRNAs are challenging due to lack of standards for quality control, normalization, and

\section{REFERENCES}

Alvarez Erviti, L., Seow, Y., Yin, H., Betts, C., Lakhal, S., and Wood, M. J. A. (2011). Delivery of siRNA to the mouse brain by systemic injection of targeted exosomes. Nat. Biotechnol. 29, 341-345.

Ambs, S., Prueitt, R. L., Yi, M., Hudson, R. S., Howe, T. M., Petrocca, F, et al. (2008). Genomic profiling of microRNA and messenger RNA reveals deregulated MicroRNA expression in prostate cancer. Cancer Res. 68, 6162-6170.

Arroyo, J., Chevillet, J., Kroh, E., Ruf, I., Pritchard, C., Gibson, D., et al. (2011). Argonaute2 complexes carry a population of circulating microRNAs independent of vesicles in human plasma. Proc. Natl. Acad. Sci. U.S.A. 108, 5003-5008.
Bartel, D. P. (2004). MicroRNAs: genomics, biogenesis, mechanism, and function. Cell 116, 281-297.

Bobrie, A., Colombo, M., Raposo, G., and Théry, C. (2011). Exosome secretion: molecular mechanisms and roles in immune responses. Traffic 12, 1659-1668.

Brase, J. C., Johannes, M., Schlomm, T., Fälth, M., Haese, A., Steuber, T., et al. (2011). Circulating miRNAs are correlated with tumor progression in prostate cancer. Int. J. Cancer 128, 608-616.

Bryant, R. J., Pawlowski, T., Catto, J. W. F., Marsden, G., Vessella, R. L., Rhees, B., et al. (2012). Changes in circulating microRNA levels associated with prostate cancer. Br. J. Cancer 106, 768-774.

statistical analysis. Together, these factors might explain most of the conflicting results.

Blood is the body fluid that traditionally has been used as the main source of cancer biomarkers, though the use of urine in cancer diagnosis and prognosis is growing. Choosing urine as a source of biomarkers has several advantages compared to blood; it is noninvasive, easily obtained in large quantities, and the composition of urine is less complex. Particularly important for prostate cancer is the fact that the composition of urine reflects alterations in the urogenital system. However, dilution of the miRNAs could be a possible drawback with the use of urine as a source of biomarkers. To our knowledge there are currently no publications describing the miRNA content of urinary exosomes in prostate cancer.

\section{CONCLUSION}

Intensive research is put into the hunt for new diagnostic and prognostic tools for prostate cancer. Representing a non-invasive approach, measurement of extracellular miRNAs in blood, urine, or other biological fluids might turn out as a valuable strategy. Studies on blood-based miRNAs as biomarkers for prostate cancer are emerging, but most of these are small-scale, vary in methodology, and lack a characterization of the form in which the extracellular miRNAs are found. Standards for miRNA quantification need to be established and larger validation studies need to be performed before conclusions can be drawn on the diagnostic potential of specific miRNAs. It might be important to distinguish between different forms of extracellular miRNAs, both for diagnosis and for understanding possible biological functions. More and large-scale studies on exosomal miRNAs in biological fluids from prostate cancer patients and healthy controls are therefore needed. Although there is still very limited knowledge about the biological roles of extracellular miRNAs and extracellular vesicles, they are currently emerging as an important source of biomarkers.

\section{ACKNOWLEDGMENTS}

This work was funded by the South-Eastern Norway Regional Health Authority and The Research Council of Norway.

Calin, G. A., Ferracin, M., Cimmino, A. Di Leva, G., Shimizu, M., Wojcik, S. E., et al. (2005). A MicroRNA signature associated with prognosis and progression in chronic lymphocytic leukemia. N. Engl. J. Med. 353, 1793-1801.

Carrington, J. C., and Ambros, V. (2003). Role of microRNAs in plant and animal development. Science 301, 336-338.

Catto, J. W. F., Alcaraz, A., Bjartell, A., De Vere White, R., Evans, C., Fussel, S., et al. (2011). MicroRNA in prostate, bladder, and kidney cancer: a systematic review. Eur. Urol. 59, 671-681.

Chen, Z.-H., Zhang, G.-L., Li, H.-R., Luo, J.-D., Li, Z.-X., Chen, G.-M., et al. (2012). A panel of five circulating microRNAs as potential biomarkers for prostate cancer. Prostate 72, 1443-1452.

Chim, S. S. C., Shing, T. K. F., Hung, E. C. W., Leung, T.-Y., Lau, T.-K., Chiu, R. W. K., et al. (2008). Detection and characterization of placental microRNAs in maternal plasma. Clin. Chem. 54, 482-490.

Cocucci, E., Racchetti, G., and Meldolesi, J. (2009). Shedding microvesicles: artefacts no more. Trends Cell Biol. 19, 43-51.

Croce, C. M. (2009). Causes and consequences of microRNA dysregulation in cancer. Nat. Rev. Genet. 10, 704-714.

Fabbri, M., Paone, A., Calore, F., Galli, R., Gaudio, E., Santhanam, R., et al. (2012). MicroRNAs bind to Tolllike receptors to induce prometastatic inflammatory response. Proc. 
Natl. Acad. Sci. U.S.A. 109, E2110-E2116.

Ferlay, J., Autier, P., Boniol, M., Heanue, M., Colombet, M., and Boyle, P. (2007). Estimates of the cancer incidence and mortality in Europe in 2006. Ann. Oncol. 18, 581-592.

Gallo, A., Tandon, M., Alevizos, I., and Illei, G. (2012). The majority of microRNAs detectable in serum and saliva is concentrated in exosomes. PLoS ONE 7:e30679. doi:10.1371/journal.pone.0030679

Gibbings, D. J., Ciaudo, C., Erhardt, M., and Voinnet, O. (2009). Multivesicular bodies associate with components of miRNA effector complexes and modulate miRNA activity. Nat. Cell Biol. 11, 1143-1149.

Hanke, M., Hoefig, K., Merz, H., Feller, A., Kausch, I., Jocham, D., et al. (2010). A robust methodology to study urine microRNA as tumor marker: microRNA-126 and microRNA-182 are related to urinary bladder cancer. Urol. Oncol. 28, 655-661.

Hatley, M., Patrick, D., Garcia, M., Richardson, J., Bassel Duby, R., van Rooij, E., et al. (2010). Modulation of K-Ras-dependent lung tumorigenesis by MicroRNA-21. Cancer Cell $18,282-293$.

Heneghan, H., Miller, N., Kelly, R., Newell, J., and Kerin, M. (2010). Systemic miRNA-195 differentiates breast cancer from other malignancies and is a potential biomarker for detecting noninvasive and early stage disease. Oncologist $15,673-682$.

Hessvik, N. P., Phuyal, S., Brech, A., Sandvig, K., and Llorente, A. (2012). Profiling of microRNAs in exosomes released from PC-3 prostate cancer cells. Biochim. Biophys. Acta 1819, 1154-1163.

Hristov, M., Erl, W., Linder, S., and Weber, P. (2004). Apoptotic bodies from endothelial cells enhance the number and initiate the differentiation of human endothelial progenitor cells in vitro. Blood 104, 2761-2766.

Hunter, M. P., Ismail, N., Zhang, X., Aguda, B. D., Lee, E. J., Yu, L., et al. (2008). Detection of microRNA expression in human peripheral blood microvesicles. PLoS ONE 3:e3694. doi:10.1371/journal.pone.0003694

Hutvagner, G., and Zamore, P. D. (2002). A microRNA in a multipleturnover RNAi enzyme complex. Science 297, 2056-2060.

Iorio, M. V., Ferracin, M., Liu, C.G., Veronese, A., Spizzo, R., Sabbioni, S., et al. (2005). MicroRNA gene expression deregulation in human breast cancer. Cancer Res. 65, 7065-7070.

Jansson, M. D., and Lund, A. H. (2012). MicroRNA and cancer. Mol. Oncol. 6, 590-610.

Jemal, A., Siegel, R., Ward, E., Hao, Y., $\mathrm{Xu}$, J., and Thun, M. J. (2009). Cancer statistics, 2009. CA Cancer J. Clin. $59,225-249$.

Johnstone, R. M., Adam, M., Hammond, J. R., Orr, L., and Turbide, C. (1987). Vesicle formation during reticulocyte maturation. Association of plasma membrane activities with released vesicles (exosomes). J. Biol. Chem. 262, 9412-9420.

Kalra, H., Simpson, R., Ji, H., Aikawa, E., Altevogt, P., Askenase, P., et al. (2012). Vesiclepedia: a compendium for extracellular vesicles with continuous community annotation. PLoS Biol. 10:e1001450. doi:10.1371/journal.pbio.1001450

Kim, Y.-K., Yeo, J., Kim, B., Ha, M., and Kim, V. N. (2012). Short structured RNAs with low GC content are selectively lost during extraction from a small number of cells. Mol. Cell 46, 893-895.

Kogure, T., Lin, W.-L., Yan, I. K., Braconi, C., and Patel, T. (2011). Intercellular nanovesicle-mediated microRNA transfer: a mechanism of environmental modulation of hepatocellular cancer cell growth. Hepatology 54, 1237-1248.

Kosaka, N., Iguchi, H., Yoshioka, Y., Takeshita, F., Matsuki, Y., and Ochiya, T. (2010a). Secretory mechanisms and intercellular transfer of microRNAs in living cells. J. Biol. Chem. 285, 17442-17452.

Kosaka, N., Izumi, H., Sekine, K., and Ochiya, T. (2010b). microRNA as a new immune-regulatory agent in breast milk. Silence 1, 7-7.

Kuner, R., Brase, J., Sultmann, H., and Wuttig, D. (2013). microRNA biomarkers in body fluids of prostate cancer patients. Methods 59, 132-137.

Lasser, C., Seyed Alikhani, V., Ekstrom, K., Eldh, M., Torregrosa Paredes, P., Bossios, A., et al. (2011). Human saliva, plasma and breast milk exosomes contain RNA: uptake by macrophages. J. Transl. Med. 9, 9.

Laterza, O., Lim, L., Garrett-Engele, P., Vlasakova, K., Muniappa, N., Tanaka, W., et al. (2009). Plasma MicroRNAs as sensitive and specific biomarkers of tissue injury. Clin. Chem. 55, 1977-1983.

Lawrie, C., Gal, S., Dunlop, H., Pushkaran, B., Liggins, A., Pulford, K., et al. (2008). Detection of elevated levels of tumour-associated microRNAs in serum of patients with diffuse large B-cell lymphoma. Br. J. Haematol. 141, 672-675.

Lee, R. C., Feinbaum, R. L., and Ambros, V. (1993). The C. elegans heterochronic gene lin-4 encodes small RNAs with antisense complementarity to lin-14. Cell 75, 843-854.

Lee, Y. S., Pressman, S., Andress, A. P., Kim, K., White, J. L., Cassidy, J. J., et al. (2009). Silencing by small RNAs is linked to endosomal trafficking. Nat. Cell Biol. 11, 1150-1156.

Lehmann, S., Krüger, C., Park, B., Derkow, K., Rosenberger, K., Baumgart, J., et al. (2012). An unconventional role for miRNA: let-7 activates Toll-like receptor 7 and causes neurodegeneration. Nat. Neurosci. 15, 827-835.

Lim, L. P., Lau, N. C., Garrett-Engele, P., Grimson, A., Schelter, J. M., Castle, J., et al. (2005). Microarray analysis shows that some microRNAs downregulate large numbers of target mRNAs. Nature 433, 769-773.

Lima, R., Busacca, S., Almeida, G., Gaudino, G., Fennell, D., and Vasconcelos, M. H. (2011). MicroRNA regulation of core apoptosis pathways in cancer. Eur. J. Cancer 47, 163-174.

Lodes, M. J., Caraballo, M., Suciu, D., Munro, S., Kumar, A., and Anderson, B. (2009). Detection of cancer with serum miRNAs on an oligonucleotide microarray. PLoS ONE 4:e6229. doi:10.1371/journal.pone.0006229

Lu, J., Getz, G., Miska, E. A., AlvarezSaavedra, E., Lamb, J., Peck, D., et al. (2005). MicroRNA expression profiles classify human cancers. Nature $435,834-838$.

Mahn, R., Heukamp, L., Rogenhofer, S., von Ruecker, A., Müller, S., and Ellinger, J. (2011). Circulating microRNAs (miRNA) in serum of patients with prostate cancer. Urology 77, 1265.e9-1265.e16.

Medina, P., Nolde, M., and Slack, F. (2010). OncomiR addiction in an in vivo model of microRNA21-induced pre-B-cell lymphoma. Nature 467, 86-90.

Mitchell, P. S., Parkin, R. K., Kroh, E. M., Fritz, B. R., Wyman, S. K., PogosovaAgadjanyan, E. L., et al. (2008). Circulating microRNAs as stable bloodbased markers for cancer detection. Proc. Natl. Acad. Sci. U.S.A. 105, 10513-10518.

Mittelbrunn, M., Gutierrez-Vazquez, C., Villarroya-Beltri, C., Gonzalez, S., Sanchez-Cabo, F., Gonzalez, M. A., et al. (2011). Unidirectional transfer of microRNA-loaded exosomes from $\mathrm{T}$ cells to antigen-presenting cells. Nat. Commun. 2, 282.
Moltzahn, F., Olshen, A., Baehner, L., Peek, A., Fong, L., Stöppler, H., et al. (2011). Microfluidic-based multiplex qRT-PCR identifies diagnostic and prognostic microRNA signatures in the sera of prostate cancer patients. Cancer Res. 71, 550-560.

Montecalvo, A., Larregina, A., Shufesky, W., Stolz, D., Sullivan, M. L. G., Karlsson, J., et al. (2012). Mechanism of transfer of functional microRNAs between mouse dendritic cells via exosomes. Blood 119, 756-766.

Mu, P., Han, Y.-C., Betel, D., Yao, E., Squatrito, M., Ogrodowski, P., et al. (2009). Genetic dissection of the miR-17 92 cluster of microRNAs in Myc-induced B-cell lymphomas. Genes Dev. 23, 2806-2811.

Nogueira, L., Corradi, R., and Eastham, J. (2010). Other biomarkers for detecting prostate cancer. BJU Int. 105, 166-169.

Ohshima, K., Inoue, K., Fujiwara, A. Hatakeyama, K., Kanto, K., Watanabe, Y., et al. (2010). Let-7 microRNA family is selectively secreted into the extracellular environment via exosomes in a metastatic gastric cancer cell line. PLoS ONE 5:e13247. doi:10.1371/journal.pone.0013247

Ozen, M., Creighton, C. J., Ozdemir, M., and Ittmann, M. (2007). Widespread deregulation of microRNA expression in human prostate cancer. Oncogene 27, 1788-1793.

Pan, B. T., Teng, K., Wu, C., Adam, M., and Johnstone, R. M. (1985). Electron microscopic evidence for externalization of the transferrin receptor in vesicular form in sheep reticulocytes. J. Cell Biol. 101, 942-948.

Park, N., Zhou, H., Elashoff, D., Henson, B., Kastratovic, D., Abemayor, E., et al. (2009). Salivary microRNA: discovery, characterization, and clinical utility for oral cancer detection. Clin. Cancer Res. 15, 5473-5477.

Pigati, L., Yaddanapudi, S. C. S., Iyengar, R., Kim, D.-J., Hearn, S., Danforth, D., et al. (2010). Selective release of microRNA species from normal and malignant mammary epithelial cells. PLoS ONE 5:e13515. doi:10.1371/journal.pone.0013515

Porkka, K. P., Pfeiffer, M. J., Waltering, K. K., Vessella, R. L., Tammela, T. L. J., and Visakorpi, T. (2007). MicroRNA expression profiling in prostate cancer. Cancer Res. 67, 6130-6135.

Pritchard, C., Kroh, E., Wood, B., Arroyo, J., Dougherty, K., Miyaji, M., et al. (2012). Blood cell origin of circulating microRNAs: a cautionary note for cancer biomarker studies. Cancer Prev. Res. (Phila.) 5, 492-497. Rabinowits, G., Gercel-Taylor, C., Day, J. M., Taylor, D. D., and Kloecker, G. 
H. (2009). Exosomal microRNA: a diagnostic marker for lung cancer. Clin. Lung Cancer 10, 42-46.

Selth, L., Townley, S., Gillis, J., Ochnik, A., Murti, K., Macfarlane, R., et al. (2012). Discovery of circulating microRNAs associated with human prostate cancer using a mouse model of disease. Int. J. Cancer 131, 652-661.

Shen, J., Hruby, G., McKiernan, J., Gurvich, I., Lipsky, M., Benson, M., et al. (2012). Dysregulation of circulating microRNAs and prediction of aggressive prostate cancer. Prostate 72, 1469-1477.

Skog, J., Wurdinger, T., van Rijn, S., Meijer, D. H., Gainche, L., Curry, W. T., et al. (2008). Glioblastoma microvesicles transport RNA and proteins that promote tumour growth and provide diagnostic biomarkers. Nat. Cell Biol. 10, 1470-1476.

Song, J.-J., Smith, S. K., Hannon, G. J., and Joshua-Tor, L. (2004). Crystal structure of argonaute and its implications for RISC slicer activity. Science 305, 1434-1437.

Sørensen, K. D., and Ørntoft, T. F. (2009). Discovery of prostate cancer biomarkers by microarray gene expression profiling. Expert Rev. Mol. Diagn. 10, 49-64.

Sverdlov, E. (2012). Amedeo Avogadro's cry: what is $1 \mu \mathrm{g}$ of exosomes? Bioessays 34, 873-875.
Szczyrba, J., Loprich, E., Wach, S., Jung, V., Unteregger, G., Barth, S., et al. (2010). The microRNA profile of prostate carcinoma obtained by deep sequencing. Mol. Cancer Res. 8, 529-538.

Tavoosidana, G., Ronquist, G., Darmanis, S., Yan, J., Carlsson, L., Wu, D., et al. (2011). Multiple recognition assay reveals prostasomes as promising plasma biomarkers for prostate cancer. Proc. Natl. Acad. Sci. U.S.A. 108, 8809-8814.

Turchinovich, A., Weiz, L., Langheinz, A., and Burwinkel, B. (2011). Characterization of extracellular circulating microRNA. Nucleic Acids Res. 39, 7223-7233.

Valadi, H., Ekstrom, K., Bossios, A., Sjostrand, M., Lee, J. J., and Lotvall, J. O. (2007). Exosome-mediated transfer of mRNAs and microRNAs is a novel mechanism of genetic exchange between cells. Nat. Cell Biol. 9, 654-659.

Vickers, K., Palmisano, B., Shoucri, B., Shamburek, R., and Remaley, A. (2011). MicroRNAs are transported in plasma and delivered to recipient cells by high-density lipoproteins. Nat. Cell Biol. 13, 423-433.

Volinia, S., Calin, G. A., Liu, C.-G., Ambs, S., Cimmino, A., Petrocca, F., et al. (2006). A microRNA expression signature of human solid tumors defines cancer gene targets.
Proc. Natl. Acad. Sci. U.S.A. 103, 2257-2261.

Weber, J., Baxter, D., Zhang, S., Huang, D., Huang, K., Lee, M., et al. (2010). The microRNA spectrum in 12 body fluids. Clin. Chem. 56, 1733-1741.

Wightman, B., Ha, I., and Ruvkun, G. (1993). Posttranscriptional regulation of the heterochronic gene lin14 by lin- 4 mediates temporal pattern formation in C. elegans. Cell 75, 855-862.

Yaman Agaoglu, F., Kovancilar, M., Dizdar, Y., Darendeliler, E., Holdenrieder, S., Dalay, N., et al. (2011). Investigation of miR-21, miR-141, and miR-221 in blood circulation of patients with prostate cancer. Tumour Biol. 32, 583-588.

Zernecke, A., Bidzhekov, K., Noels, H., Shagdarsuren, E., Gan, L., Denecke, B., et al. (2009). Delivery of microRNA-126 by apoptotic bodies induces CXCL12-dependent vascular protection. Sci. Signal. 2, ra81ra81.

Zhang, H.-L., Yang, L.-F., Yao, X.-D. Zhang, S.-L., Dai, B., Zhu, Y.-P., et al. (2011). Serum miRNA-21: elevated levels in patients with metastatic hormone-refractory prostate cancer and potential predictive factor for the efficacy of docetaxelbased chemotherapy. Prostate 71 , 326-331.

Zhang, Y., Jia, Y., Zheng, R., Guo, Y., Wang, Y., Guo, H., et al.
(2010). Plasma microRNA-122 as a biomarker for viral-, alcohol-, and chemical-related hepatic diseases. Clin. Chem. 56, 1830-1838.

Zheng, C., Yinghao, S., and Li, J. (2012). MiR-221 expression affects invasion potential of human prostate carcinoma cell lines by targeting DVL2. Med. Oncol. 29, 815-822.

Conflict of Interest Statement: The authors declare that the research was conducted in the absence of any commercial or financial relationships that could be construed as a potential conflict of interest.

Received: 22 January 2013; accepted: 02 March 2013; published online: 21 March 2013.

Citation: Hessvik NP, Sandvig K and Llorente A (2013) Exosomal miRNAs as biomarkers for prostate cancer. Front. Genet. 4:36. doi 10.3389/fgene.2013.00036

This article was submitted to Frontiers in Non-Coding RNA, a specialty of Frontiers in Genetics.

Copyright (c) 2013 Hessvik, Sandvig and Llorente. This is an open-access article distributed under the terms of the Creative Commons Attribution License, which permits use, distribution and reproduction in other forums, provided the original authors and source are credited and subject to any copyright notices concerning any third-party graphics etc. 